\title{
PACM HCI V4 ISS, November 2020 - Editorial
}

\author{
FANNY CHEVALIER, University of Toronto \\ NICOLAI MARQUARDT, University College of London
}

\begin{abstract}
CCS Concepts: • Human-centered computing $\sim$ Human computer interaction (HCI) $\sim$ Interactive systems and tools
\end{abstract}

\section{ACM Reference format:}

Fanny Chevalier, Nicolai Marquardt. 2020. PACM HCI ISS November 2020 - Editors' Message. PACM Hum.-Comp. Interact. 4, ISS, Article 182 (November 2020). https://doi.org/10.1145/3427310

\section{INTRODUCTION}

It is our great pleasure to welcome you to this issue of the Proceedings of the ACM on Human Computer Interaction, the first to focus on the contributions from the research community Interactive Surfaces and Spaces (ISS). Interactive Surfaces and Spaces increasingly pervade our everyday life, appearing in various sizes, shapes, and application contexts, offering a rich variety of ways to interact. This diverse research community explores the design, development and use of new and emerging tabletop, digital surface, interactive spaces and multi-surface technologies.

The call for articles for this issue on ISS attracted 87 submissions, from all over the world. After the first round of reviewing, 26 (29.9\%) articles with minor revisions were invited to the Revise and Resubmit phase, and 39 (44.8\%) articles with major revisions for the next full PACMHCI ISS review cycle in 2021 (total of 65 articles, 74.7\%). The editorial committee worked hard over the two iterations of the review process to arrive at final decisions. In the end, 25 articles (28\%) were accepted. All authors of the accepted articles are invited to present at the ISS conference from November 8-11, 2020.

This issue exists because of the dedicated volunteer effort of 31 senior editors who served as Associate Chairs (ACs), and 146 expert reviewers to ensure high quality and insightful reviews for all articles in both rounds. Reviewers and committee members were kept constant for papers that submitted to both rounds.

\footnotetext{
Permission to make digital or hard copies of part or all of this work for personal or classroom use is granted without fee provided that copies are not made or distributed for profit or commercial advantage and that copies bear this notice and the full citation on the first page. Copyrights for third-party components of this work must be honored. For all other uses, contact the Owner/Author.

(c) Copyright 2020 held by Owner/Author 2573-0142/2020/11 ... Art. 182

https://doi.org/10.1145/3427310
}

PACM on Human-Computer Interaction, Vol. 4, No. ISS, Article 82, Publication date: November 2020. 